\title{
Annotated Bibliography of Remote Sensing Methods for Monitoring Desertification
}

GEOLOGICAL SURVEY CIRCULAR 851
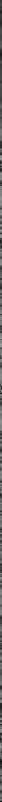



\section{Annotated Bibliography of Remote Sensing Methods for Monitoring Desertification}

By A. S. Walker and Charles J. Robinove GEOLOGICALSURVEYCIRCULAR 851 





\title{
Annotated Bibliography of Remote Sensing Methods for Monitoring Desertification
}

\author{
By A.S. Walker and Charles J. Robinove
}

\begin{abstract}
Remote sensing techniques are valuable for locating, assessing, and monitoring desertification. Remotely sensed data provide a permanent record of the condition of the land in a format that allows changes in land features and condition to be measured. The annotated bibliography of 118 items discusses remote sensing methods that may be applied to desertification studies.
\end{abstract}

\section{INTRODUCTION}

The purpose of this report is to briefly evaluate the ways in which remote sensing can contribute to our knowledge of factors which cause or exacerbate desertification and to list sources of additional information. In addition to presenting a brief state-of-the-art look at the use of remote sensing in monitoring desertification, this review and annotated bibliography is intended to increase interest in and support for the use of techniques by remote sensing researchers and individuals with responsibilities for planning and decisionmaking in areas subject to desertification.

The bibliography is not an exhaustive one, although we have tried to make it representative. We wish to thank William Doyel and Patricia Paylore for reviewing this paper and suggesting several significant references.

\section{DESERTIFICATION}

Desertification, here considered as the decrease of productivity of arid and semiarid lands, has led to widespread starvation, severe decreases in food supplies, and disruption of land use patterns both along the perimeters of many of the world's natural deserts and far from these deserts. Although the phenomenon has been observed throughout human history, the term "desertification" has only been used in this decade. There is not, as yet, a generally accepted rigorous definition of the term. The United Nations Plan of Action to Combat Desertification defines desertification as

"the diminution or destruction of the biological potential of the land, [which] can lead ultimately to desert-like conditions. It is an aspect of the widespread deterioration of ecosystems, and has diminished or destroyed the biological potential *** for multiple use purposes at a time when increased productivity is needed to support growing populations in quest of development. * * * In general, the quest for even greater productivity has intensified exploitation and has carried disturbance by man into less productive and more fragile lands. Overexploitation gives rise to degradation of vegetation, soil, and water. * * Desertification is a self-accelerating process, feeding on itself, and as it advances, rehabilitation costs rise exponentially" (Reining, 1978b, p. 3).

Desertification can have both natural and manmade components, which may reinforce each other. For example, the practice of intensive livestock grazing during a series of naturally dry years represents an extreme in the desertification process.

Desertification was first brought to world attention in the 1930's when parts of the Great Plains of the United States turned into the Dust Bowl as a result of poor farming practices initiated during a "wet" cycle. Millions were forced to abandon their farms and their livelihoods. By 1973, drought that started in 1968 in the Sahelian countries of Africa was responsible for the deaths of between 100,000 and 250,000 individuals, the disruption of millions of other lives, and the collapse of the agricultural bases of five countries. Over $\$ 200$ million in cash and food were donated by private individuals, governments, and the United Nations in an effort to prevent mass starvation. Reining (1978b) estimates that desertification currently affects more than 600 million people and one-third of the Earth's land surface. 

combining the four Landsat bands. Visually, the resulting enhancement is equal to the more expensive computer enhancement; however, quantitative control of the process is lacking.

Standard and enhanced Landsat images can be used to inventory land use and monitor surficial changes in areas susceptible to or undergoing desertification. The images may be used to locate, assess, and monitor changes in vegetation, soil, water, and land use. El-Shazly and others (1977a, 1977b, 1978) use transparencies of Landsat bands 5 and 7 images to delineate water-bearing units and to map present and former drainage systems in arid lands in Egypt. They also compare sand-dune belts interpreted from Landsat images with those mapped by the survey of Egypt 45 years previously and find that the belts have moved a considerable distance. Hielkema (1977) studies temporal tonal variations on black-and-white Landsat multispectral scanner (MSS) images and correlates the variations with ground-collected data.

In addition to standard mapping techniques, Robinove (1979) has suggested a second method in which Landsat images may be used. He notes that terrain brightness, as measured by Landsat scanners, represents an integration of reflectance from the terrain features and is therefore more easily correlated with integrated terrain units than with differentiated units. Integrated terrain maps produced from Landsat images combine several terrain characteristics into each map unit, which then is more directly related to land use and to methods of land management than is any single characteristic.

Landsat data of a particular scene may be registered with a second set of Landsat data of the scene taken at a different time. Temporal variations between the two sets of data may then be measured quantitatively by a computer or qualitatively through use of a simple optical device. Landsat data collected since 1972 are available for most areas of the world, although coverage of areas far from ground-receiving stations may be sparse. An early Landsat image of an area may be used as a relative baseline with which to compare recent changes.

Remotely sensed data may be used in a digital format to calculate statistical information. The information obtained may be recorded as a histogram, a graph, or a new image. Hielkema (1977) uses principal component analysis for monitoring arid land vegetation. He finds that the third principal component highlights vegetation, and that combining the three principal components into a new FCC shows vegetation better than does a regular FCC. He feels that vegetation changes may be closely monitored with this method. Lodwick (1979a) equates the second principal component with "greenness," the quality and quantity of vegetation, and suggests that changes in the second principal component may reflect changes in ecology caused by seasonal variations or by human interference.

Thompson and Wehmanen $(1977,1978)$ use transformed Landsat digital data to calculate a Green Index Number (GIN). The index number represents the percentage of picture elements in a Landsat scene having a "Green Number" greater than 15. A "Green Number" is a computer-derived measure of the amount of green vegetation present in a pixel; zero indicates bare soil and 15 indicates good vegetative cover. A plot of the GIN versus time for a normal segment of land follows a predetermined curve. Any deviation from this curve indicates that the area is undergoing drought. The method has been used to monitor agricultural areas but has not yet been applied to arid-land native vegetation.

Robinove and others (1981) use Landsat digital data to calculate albedo changes of arid terrain in Utah. Using registered multitemporal digital Landsat data, they calculate albedo differences in percentage and produce an image displaying the albedo increase or decrease. They find that many of the phenomena that tend to lower productivity of arid-land ecosystems will tend to make the land brighter on the image. These phenomena include decreased density of vegetation, increased erosion, and movement and deposition of wind-blown materials. Phenomena that increase productivity of arid-land ecosystems may tend to darken the land. These include increased density of vegetation and increased soil moisture. This monitoring system provides data on whether the land in a given area has brightened or darkened over a given period of time; these data may then be calibrated with ground data collected only in those areas where change has occurred. This approach provides a cost-efficient means of using remotely sensed data and, at the same time, provides for the acquisition of quantitative ground data at critical points.

The application of data from other imaging and nonimaging orbital sensors to desertification studies needs to be further investigated. Nimbus data of northern Africa have been used by Allison (1977) and Obuolowu (1977) to study moisture 
patterns and vegetation boundaries. McCauley and others (1979) used Geostationary Operational Environmental Satellite (GOES) images to locate, measure, and study two dust plumes.

Blom and others (1979) compare Seasat synthetic aperture radar images of the Algodones dunes and Sonora dunes in southwestern North America with Landsat return beam vidicon images and aerial photographs. Their results suggest that the morphology of the larger dune features is well seen on the radar images. Comparison of ascending and descending passes indicates some differences in the signatures between the two returns.

Few studies have been done on the applicability of orbital photographs (rather than images) to desertification, partly because few repetitive orbital photographs are available. Pesce (1968) traces the southward migration of sand in Libya by analyzing Gemini photographs. Slezak and ElBaz (1979) use a zoom transfer scope to superimpose two orbital photographs taken several years apart to detect temporal changes of arid regions. They find an increase of vegetation west of the Nile River delta of approximately $1100 \mathrm{~km}^{2}$ in 10 years. Few vertical or near-vertical orbital photographs are available for these types of studies, however, and further work must await the launch of the space shuttle which will provide photographs from the Large Format Camera.

\section{AERIAL REMOTE SENSING}

Aerial photographs and data also may be used to provide information on desertification. Gwynne and Croze (1975a) and Croze and others (1978) suggest that systematic reconnaissance flights can be used for ecological monitoring and resource assessment. Other sensors including radar (Batlivala and Ulaby, 1977) and infrared scanners may be used to monitor soil moisture and other desertification indicators.

Dejace and others (1979) mapped soil moisture and evaporation from day and night thermal images and visible light photographs. They conclude that a rapid variation of albedo or of surface roughness may affect the results of the measurement unless the variations are corrected at an individual pixel level.

Millard and others (1977) measured crop canopy temperatures with thermal-infrared and colorinfrared systems. They use the data to calculate a stress-degree day (SDD) and believe it indicates plant water needs and may be used to determine irrigation scheduling. The results establish the su- periority of thermal-infrared images to colorinfrared photographs for such work.

To plan a study of desertification based on remote sensing methods, the user must consider from what altitude the data should be collected, based on the minimum resolution requirement for the project and the scale, and the cost of obtaining the data. When the scale has been determined, the user must decide the type of data to be used and the format of the data.

\section{CONCLUSIONS}

Remote sensing methods, both orbital and aerial, are valuable for locating, assessing and monitoring areas of desertification, but they must be used in conjunction with ground-collected data. An appropriate combination of the two will result in data that will provide a basis for planning and decisionmaking. The most efficient approach is to use remote sensing methods to detect areas of desertification or areas where the terrain has changed and to use ground methods to identify the cause of change and the possible remedial actions.

The user must also consider the fact that remote sensing methods are quite inexpensive per unit of data as compared to ground methods. The rationale for the use of remote sensing methods is to minimize the amount of ground data needed to ensure the validity of the remotely sensed data.

The application of remotely-sensed data to desertification studies is in the experimental stage. More research is needed on the use of such data to identify indicators of desertification and how they reflect the processes; on the rates of degradation or reclamation; on identifying a base for measuring the process; and on data presentation formats.

Although remote sensing methods have been used in studying desertification processes, the choice of methods, or the combination of methods, that is most practical and efficient for routine monitoring of both large and small areas needs additional investigation. The potential contribution of non-Landsat satellite sensors and quantitative information on how much field work is necessary to support a given sensor in a given area are unknown.

The annotated bibliography is restricted to papers concerning changes in arid and semiarid lands and their monitoring by remote sensing methods. It purposely does not attempt to cover the voluminous literature on the use of remote 


Bentley, R. G., 1978, Recommendations for a study to test the feasibility of monitoring indicators of desertification in West Africa using ground data, large-scale aerial photography and Landsat data: Washington, D.C., U.S. Agency for International Development, $36 \mathrm{p}$.

A research project is designed to monitor the process of desertification using remote sensing as a tool. The author discusses the social situation in the Sahel, implications for U.S. programs, and makes recommendations for the U.S. AID program. A literature review is included.

Bentley, R. G., Salmon-Drexler, B. C., Bonner, W. J., and Vincent, R. K., 1976, A Landsat study of ephemeral and perennial rangeland vegetation and soils: Washington, D.C., Bureau of Land Management, $234 \mathrm{p}$.

Landsat data are processed by computer to map vegetation characteristics of perennial rangeland in Montana and of ephemeral rangeland in Arizona. The choice of processing techniques depends on prescribed mapping tasks and site conditions. Techniques such as maximum likelihood classification are useful for recognizing the plant communities in Montana. Other techniques such as density slicing of images are more effective in sparsely vegetated Arizona. Landsat sensors are more sensitive to differences between plant communities based on percent of vigorously growing vegetation than to actual physical or spectral differences among species. An operational system for the Bureau of Land Management is recommended.

Berkofsky, L., 1976, Effect of variable surface albedo on the atmospheric circulation in desert regions: Journal of Applied Meteorology, v. 15, p. 1139-1144.

A desert circulation model is developed which includes a vertically parameterized boundary layer. The model is used to investigate circulation in the northern Negev. The vertical velocity at the tip of the boundary layer is related to net radiative heating (function of albedo), convective heating, and ground friction. The author's calculations imply that lowering surface albedo may lead to increased vertical velocity and increased rainfall.

Berry, L., and Ford, R. B., 1977, Recommendations for a system to monitor critical indicators in areas prone to desertification: Worcester, Mass., Clark University, 187 p.
An interlinked monitoring system is proposed to join together a small and selective global monitoring program with local, national, and regional monitoring activities. At the global level, albedo, duststorms, rainfall, soil erosion, sedimentation, and salinization should be monitored. The authors recommend the use of satellite images for all levels of monitoring.

Blom, R. G., Daily, M. I., Elachi, C., and Saunders, R. S., 1979, Analysis of Seasat SAR images of sand dunes, in Reports of Planetary Geology Program, 1978-79: National Aeronautics and Space Administration, Technical Memorandum 80339, p. 359-361.

Seasat SAR (synthetic aperture radar) images of the Algodones dunes, southeastern California, and the Sonora dunes, northwestern Mexico, are compared with Landsat 3 return beam vidicon data and aerial photographs. Results show that the dune morphology is well expressed in the radar images, and a comparison of images from ascending and descending passes indicates a difference in signatures between the two types of passes.

Brera, A., and Shahrokhi, F., 1978, Application of Landsat data to monitor desert spreading in the Sahara region: International Symposium on Remote Sensing of Environment, 12th, Proceedings, p. 1329-1335.

Desert dunes in Africa are now advancing at the rate of 30 miles per year in spite of the fact that sand fixation and afforestation methods have been undertaken by many countries. Satellite images are used to analyze and define factors relating to dune movement, formation, and growth. The authors use 1972-77 digital Landsat data of a test site in the Libyan Desert to identify and map distinct units on the ground. From comparison of temporal data, the authors conclude that global surveillance of the status of dryland ecosystems and land use can be achieved most economically with Landsat images.

Casimir, M.J., Winter, R.P., and Glatzer, Bernt, 1980, Nomadism and remote sensing: animal husbandry and the sagebrush community in a nomad winter area in western Afghanistan: Journal of Arid Environments, v. 3, p. 231-254.

The authors use Landsat digital data to augment field-collected data on the amount and types of biomass and herd animals in a winter grazing area of the Pashtan nomads. They calculate the 
available annual food plant growth and compare it with the estimated herd requirement and the estimated fuel requirement. During the 1976-77 winter, 23-32 percent of the annual food plant growth was consumed in the nomad economy. The authors find that the first principal component shows more detail than do any of the original Landsat bands, and that unfiltered data are best for classification and statistics.

Centre National de la Recherche Scientifique, 1978, Contribution à l'analyse écologique des zones arides de Tunisie avec l'aide des données de la télédetection spatial. (Contribution to the ecological analysis of the arid zones of the Tunisia area using spatial remote sensing): Experience ARZOTU, Rapport final 1975-78, Centre National de la Recherche Scientifique, Montpellier, France, 222 p.

The arid zone of Tunisia (ARZOTU) experiment, based on the use of Landsat data, sought to achieve small-scale cartographic mapping of ecological zones, land use, and desertification conditions, and to determine the usefulness of multitemporal satellite data for regional ecological modeling. Based on the results of the experiment, a comprehensive view is presented of the potential uses of spatial remote sensing techniques in the arid areas along the northern fringe of the Sahara. Recommendations are made for the implementation of a spatial remote sensing experiment, in view of the opportunities for using these techniques in developing countries of the Mediterranean arid zone. The report contains a bibliography of 230 items.

Charney, J. G., 1975, Dynamics of deserts and drought in the Sahel: Quarterly Journal of the Royal Meteorological Society, v. 101, p. 193-202.

The high albedo of a desert contributes to a net radiative heat loss relative to desert surroundings. The horizontal temperature gradients on desert borders induce a frictionally controlled circulation that imparts heat aloft and maintains thermal equilibrium through a sinking motion and adiabatic compression. This gradient is superimposed on the descending branch of the mean Hadley circulation, but it is more intense. The author argues that reduction in vegetation increases albedo, causing the sinking motion and perpetuating the arid conditions. A biogeophysical feedback mechanism leads to instabilities on borders of deserts which may be set off by anthropogenic influences.
The author concludes that the Sahel drought may have been caused by overgrazing.

Coiner, J. C., 1980, Using Landsat to monitor changes in vegetation cover induced by desertification processes: International Symposium on Remote Sensing of Environment, 14th, Ann Arbor, Mich., Proceedings, p. 1341-1352.

Using a test site on the Niger River delta in Mali, west Africa, the author compares the correlation coefficient for two Landsat multispectral scanner bands on images acquired in 1973 and 1975 to produce a vegetation status map for each of the 2 years, and a vegetation change map.

Colwell, R. N., and Carneggie, D. M., 1971, Applications of remote sensing to arid-land problems, in McGinnies, W. G., and others, eds., Food, fiber, and the arid lands: Tucson, University of Arizona Press, p. 173-186.

The authors discuss the need for resource surveys to manage and properly exploit arid and semiarid regions of the world. The most efficient type of resource survey would involve remote sensing from aircraft or spacecraft. These remote sensing methods are especially applicable because of the relatively cloud-free conditions in arid lands. After reviewing the specifications of remote sensing and the type of information desired, the authors conclude that the best technique is multistage, multispectral sampling utilizing aircraft, spacecraft, and ground data. The characteristics of infrared Ektachrome film are discussed, and a photointerpretation key of the following major land use categories is presented: urban lands, agricultural croplands, uplands, rangelands, bottomlands (stream channels and washes), and salt flats. Photographs of the Phoenix, Ariz., area are included to illustrate these categories. Large-scale aerial photographs are used to illustrate the problems of identifying vegetation by subsampling (from Paylore, 1976a).

Condon, R. W., 1978, Land tenure and desertification in Australia's arid lands: Search, v. 9, no. 7, p. 261-264.

The author discusses ways in which the views and activities of early pastoral peoples and land administrators in Australia contributed to severe pasture degeneration and erosion of the more fragile landscapes. He describes factors that have modified the rate of degeneration since the widespread drought of the 1940 's including lease 


and studying their geomorphic environment. The authors find that crescentic dunes occur mostly in depressions. Where belts of longitudinal dunes cross escarpments, they break up into fields of crescentic dunes which move rapidly to inundate roads and agricultural fields.

El-Etr, H. A., and Yousif, M. S. M., 1978, Utilization of "Landsat" images and conventional aerial photographs in the delineation of some aspects of the geology of the central Eastern Desert, Egypt (abs.): Precambrian Research, v. 6, p. A14-A15.

The applications of Landsat images to fluvial features and drainage patterns in the Eastern Desert are discussed.

El-Shazly, E. M., Hady, M. A. A., and El-Kassas, I. A., 1977a, Delineation of land features in Egypt by Landsat satellite images: Annual Remote Sensing of Earth Resources Conference, 6th, Tallassee, Tennessee, Proceedings, p. 277-294.

Several examples are presented of the application of Landsat images to analyses of land features in Egypt. In one case, the authors compare sanddune belts interpreted from Landsat images with those mapped by the survey of Egypt 45 years previously and find that the belts have moved a considerable distance eastward.

El-Shazly, E. M., Hady, M. A. A., and El-Shazly, M. M., 1977b, Groundwater studies in arid areas in Egypt using Landsat satellite images: International Symposium on Remote Sensing of Environment, 11th, Ann Arbor, Mich., Proceedings, p. 1365-1372.

Landsat images are used to determine the nature of geological and lithologic units, structural lineaments, present and past drainage systems, and the distribution and form of water pools. The images are also used for analyzing geomorphic units, weathering surfaces and other weathering phenomena, desert soils, sand dunes, and salt crusts and other surface expressions of salinization. In the northern Western Desert, ground water comes to the surface along fault lines and fracture systems, and thus, analysis of Landsat images may help locate ground water supplies. The authors use positive transparencies of bands 5 and 7, false-color composites, and computercompatible tapes to delineate the water-bearing units.
El-Shazly, E. M., Hady, M. A. A., El-Shazly, M. M., El-Ghawaby, M. A., Salman, A. B., El-Kassas, I. A., Khawasik, S. M., El-Rakaiby, M. M., and El-Amin, H., 1978, Jonglei canal project, Sudan, a Landsat imagery approach: International Symposium on Remote Sensing of Environment, 12th, Ann Arbor, Mich., Proceedings, p. 1563-1572.

Landsat images are used for regional mapping and study of the Jonglei Canal Project, and are especially valuable in view of the inaccessibility of the area during the rainy season. Using Landsat images, low reconnaissance aerial photographs and ground truth and laboratory analyses, maps are constructed to show geological and environmental units, structural lineations, lineation density, surface drainage, surface water bodies, ground-water potential, soils, land use, vegetation, and infrastructure. Analysis of Landsat images provided a regional picture of a $165,000-\mathrm{km}^{2}$ area at a scale of $1: 500,000$ in less than 18 months.

El-Shazly, E. M., Hady, M. A. A., El-Shazly, M. M., El-Ghawaby, M.A., Khawasik, S. M., Haraga, A.A., Sanad, S., and Attia, S. H., and others, 1978, Application of Landsat imagery in the geological and soil investigations in the central Western Desert, Egypt: International Symposium on Remote Sensing of Environment, 12th, Ann Arbor, Mich., Proceedings, p. 857-866.

Landsat images are used to produce soils, geologic, environment, lineament and drainage maps of the central Western Desert at a scale of 1:500,000. Ground truth data, including soil profiles and lithostratographic sections, are used to verify interpretations. The authors use the maps to select and rate the most appropriate locations for desert development.

Fryberger, S. G., and Ahlbrandt, T. S., 1979, Mechanisms for the formation of eolian sand seas: Zeitschrift für Geomorphologie, v. 23, p. 440-460.

The authors compare sand features visible on Landsat images with surface wind data from weather stations to support assertions that large quantities of sand can be driven long distances across deserts by wind. By comparing regional wind regimes (including potential sand-moving wind energy and trends in direction of sand drift) to the positions of modern sand seas, the authors find that regional systems of sand drift may 
deliver much of the sand. The authors feel that in some areas regional wind systems are as important in depositing sand as are aqueous systems.

Ghose, Bimal, Kar, Amal, and Husain, Zahid, 1979, The lost courses of the Saraswati River in the Great Indian Desert: new evidence from Landsat imagery: The Geographical Journal, v. 145 , p. $446-451$.

The authors use Landsat band 7 images to trace abandoned courses of the Saraswati River in northwestern India. The former drainage systems are represented on the images by belts of discontinuous patches of dark gray. Field investigations confirm the existence of the abandoned courses and the relationship of good water wells to the courses. The authors suggest that either advancing sand and aridity or mild tectonism is responsible for the westward shift of the river.

Glantz, M. H., 1977, The U.N. and desertification: dealing with a global problem, in Glantz, M. H., ed., Desertification-environmental degradation in and around arid lands: Colorado, Westview Press, p. 1-15.

Using Rapp's (1974) definition of desertification, the author describes the process on a global scale, although he argues that desertification is primarily national in cause and national in effect. He cites as evidence satellite images showing changes across national boundaries. Desertification from an international and a national viewpoint is discussed.

Gonzales, Martin, 1978, Use of indicators in the Mexican experimental station (abs.): American Association for the Advancement of Science, National Meeting, 144th, Washington, D.C., Proceedings, p. 52-53.

The applications of the United Nations indicators for desertification to test areas of Mexico are discussed. The author reports on the success of working parties in different locales who are comparing indicators on a regional basis.

Gwynne, M. D., and Croze, Harvey, 1975, East African habitat monitoring practice: A review of methods and application, in Pagot, J. R., ed., Evaluation and mapping of tropical African rangelands Seminar: Bamako, Mali, Proceedings, p. 95-135.

A review is presented of methods used to monitor habitats, the results of the various methods, and the applicability of the results. An ecological monitoring system must be designed to collect data on environment (climate, topography, soils, flora, and hydrology), wildlife, and human and domestic animal land use patterns. Aerial photographs, ground truth data, and satellite images are all considered applicable to ecological monitoring.

Hacker, R. B., 1978, Use of large-scale aerial photographs for ecological studies in a grazed arid ecosystem: International Symposium on Remote Sensing of Environment, 12th, Ann Arbor, Mich., Proceedings, p. 1895-1908.

Color aerial photographs at a scale of 1:250 are used to obtain plant inventories for six study sites in a multilayer arid-zone community. Species are divided into size classes based on canopy area. Variations in grazing pressure are the major factor influencing community patterns in the three sites. Responses of the various plant species to grazing are defined.

Hady, M. A., El-Shazly, E.M., and Myers, V., 1979, The use of remote sensing for monitoring desertification processes and natural resources in desert and arid lands: Advances in Deserts and Arid Land Technology and Development, v. 1, Harwood academic publishers, New York, p. 399-410.

The objectives of a monitoring program for desertification are: to assess existing ecological and resource conditions, to detect physical indicators of desertification, and to observe changes representative of improvement or deterioration of natural resources. The authors believe the solutions to the desertification problem must be found on a regional or national level. The authors suggest Landsat and National Oceanic and Atmospheric Administration (NOAA) satellite images be used for monitoring desertification signatures, especially with regard to the amount of soil moisture.

Hare, F., Kates, R., and Warren, A., 1977, The making of deserts: climate, ecology, and society: Economic Geography, v. 53, p. 332-346.

The authors assert that desertification, the aggravation or extension of natural conditions, is caused by society's search for secure livelihoods in dry environments. Natural drought accentuates but does not cause the process. The authors believe that desertification is difficult to detect at a 


the Carex physodes marks the end of the optimal period. Panchromatic, infrared, and false-color films are suggested for multiband photographs. The author prefers wavelengths of 400-525 nanometers $(\mathrm{nm})$ and 600-674 $\mathrm{nm}$ for deserts, and 600-675 nm and 750-850 nm for cultural features. The author discusses wind erosion maps, maps of sand types suitable for afforestation, maps of forests damaged by insects, and maps showing the distribution of harmful substances and salts in water and soils.

Kharin, N. G., 1977, Remote-sensing techniques and the monitoring of desertification processes in arid areas: Moscow, Turkmen Academy of Sciences, Institute of Deserts, $31 \mathrm{p}$.

The author presents a brief survey, including definitions and terms and technical means used for monitoring of desertification processes. The author uses an increase in arid territories of Turkmeniya as an example of climatic desertification caused by the drying up of vegetation in years of scanty precipitation, followed by the emergence of moving sands. Anthropogenetic desertification may be found near water wells, population centers, roads, and other similar areas. Desertification may also be caused by natural calamities, such as floods of unusual scope or fires. Using these three types of desertification, the author illustrates how the use of remote sensing techniques can contribute to desertification monitoring.

Kowalik, W. S., Marsh, S. E., and Lyon, R. J. P., 1978, The effect of several atmospheric corrections on Landsat 5/4 ratios: Palo Alto, Calif., Stanford University, Technical Report 78-11, $41 \mathrm{p}$.

Ratios of multispectral scanner bands 5 and 4 from Landsat 2 computer-compatible tapes are compared for several test sites including 10 typical desert surfaces. Atmospherically corrected ratios, whether corrected by conversion to reflectance or by subtraction of dark-value path-radiance, are on the average superior to raw Landsat band 5 and 4 ratios except in areas of poor illumination or low reflectance. In these areas errors are introduced to ratios of small numbers by the atmospheric corrections. To compensate for these errors, the authors suggest a differential atmospheric correction using the path-radiance subtraction for high-digital numbers and a progressively lowersubtracted value for lower radiances. This approach avoids the apparent error introduced to ratios of small numbers by the atmospheric correction and thus provides more accurate calculations for poorly illuminated or low-reflectance sites.

Le Houerou, H. N., 1976, Rehabilitation of degraded arid lands, in Rapp, A., Le Houerou, $\mathrm{H}$. N., and Lundholm, B., eds., Can desert encroachment be stopped? A study with emphasis on Africa: Swedish Natural Science Research Council, Ecological Research Bulletin, no. 24 , p. 189-205.

Based on the premise that desertification is man-induced but aggravated by climatic circumstances, any measure for halting further loss of productivity will have to interfere with human activities. The author believes that cures for desertification have been known for a long time. Methods for biological recovery in desertified areas include: rural afforestation, sand-dune stabilization, soil water budget improvement, and better management of saline soils, and waters. Satellite images are considered helpful for monitoring desertification and evaluating the success of reclamation projects.

Lodwick, G. D., 1979, Measuring ecological changes in multitemporal Landsat data using principal components: International Symposium on Remote Sensing of Environment, 13th, Ann Arbor, Mich., Proceedings, p. 1131-1141.

Seven Landsat images of upper Hunter Valley, New South Wales, a nonagricultural countryside, are used for principal component analysis. The author finds that the first component is "brightness," related to the form and nature of the terrain, particularly its aspect. The second principal component reflects "greenness," the quality and quantity of vegetation. Changes in the principal components reflect changes in the ecology caused by seasonal changes or human influence.

Long, G., Lacaze, B., Deblissche, G., Le Floc'h, E., Sta-M' Raid, M., Pontaniev, R., and Le Cocq, A., 1977, Experimentation sur l'utilisation des données Landsat pour l'etude écologique des zones arides de Tunisie (Arzotu experiment): Canadian Symposium on Remote Sensing, 4th, Quebec, 1977, Proceedings, p. 365-375.

The report summarizes the experience of the ARZOTU experiment, begun in 1974, in several desert areas of Tunisia. The ARZOTU studies cover an area of approximately $50,000 \mathrm{~km}^{2}$ between the 
100 and $350 \mathrm{~mm}$ rainfall isohyets. Objectives of the experiment included an inventory of surface landforms, soils, vegetation, and ecology, as well as cartographic potential. Results of the inventory are tabulated by area. Applications of remote sensing techniques are described.

McCauley, J. F., Breed, C. S., Grolier, M. J., and MacKinnon, D. J., 1979, The U.S. dust storm of February, 1977, in Pewe, T. L., ed., Desert dust: origin, characteristics, and effect on man: Geological Society of America, Special Paper (in press).

GEOS-1, a geostationary weather satellite, imaged two dust plumes of the first winter storm of 1977. The location, direction, and obscured ground surface were measured from the satellite images. The vastness of this storm suggests that atmospheric transport of dust eastward from the Great Plains to the Atlantic Ocean may be of sedimentologic significance.

McGinnies, W. G., 1970, An annotated bibliography and evaluation of remote-sensing publications relating to military geography of arid lands: U.S. Army Earth Sciences Laboratory, Technical Report 71-27-ES, $107 \mathrm{p}$.

A 355-reference annotated bibliography is presented of remote-sensing publications related to military geography of arid lands. The publication includes summary tables of the applications of varied remote sensing techniques to terrain, groundwater, soils, cultural features, flora, fauna, weather and climate, coastal zones, and general geography.

McGinnies, W. G., 1974, A study to explore the use of orbital remote sensing to determine native arid plant distribution: Tucson, University of Arizona, Office of Arid Land Studies, $36 \mathrm{p}$.

Results of the research include a method for determining the reflectivities of natural areas from ERTS data taking into account Sun-angle atmospheric effects on the radiance seen by the satellite sensor. Ground truth spectral signature data for various types of scenes, including ground with and without annuals and various shrubs, are collected. Large areas of varnished desert pavement are visible and mappable in ERTS and highaltitude aircraft images. A large-scale and a small-scale vegetation pattern are found to be correlated with presence of desert pavement. A comparison of radiometric data with video recordings shows quantitatively that for most areas of desert vegetation, soils are the most influential factor in determining the signature of a scene. Additive and subtractive image-processing techniques are applied in the darkroom to enhance vegetational aspects of ERTS images (from Paylore, 1976).

McKee, Edwin, 1974, An investigation of major sand seas in desert areas throughout the world: ERTS Symposium, 3d, Washington, D.C., v. 1, Proceedings, NASA SP-351, p. 655-679.

Landsat images are used to investigate sand seas on a global scale. One of the objectives of this study is to gain insight into the controls of sand migration. Fifteen major sites in the Eastern Hemisphere and three in the Western Hemisphere are examined on mosaics of false-color prints. The author proposes that sand bodies be classified into five principal types: parallel straight or linear, parallel wavy or crescentic, star or radial, parabolic, and sheet or stringer types. Each group has numerous variations. Controlling factors in forming the types of sand bodies are: wind direction and strength, topography, vegetation, moisture, available sediment, and distance from source. The author attempts to recognize and delineate these factors. Ground investigations are used to determine the internal structures of sand masses.

McKee, E. D., Breed, C. S., and Fryberger, S. G., 1977, Desert sand seas, in Skylab Explores the Earth: Johnson Space Center, NASA SP-380, p. 5-48.

The authors report on the results of Skylab 4 analysis of desert sand seas. Handheld camera photographs from space and visual observations are used for studying regional patterns, preparing maps, and classifying eolian sand deposits. This information may contribute to understanding dune movement and predicting future environments conducive to sand deposition.

McKee, E. D., Breed, C. S., and Harris, L. E., 1973, A study of morphology, provenance, and movement of desert sand seas in Africa, Asia, and Australia: Symposium on Significant Results Obtained from ERTS-1, NASA Proceedings v. 1, p. 291-303.

Major types of desert sand seas are classified on the basis of morphologic pattern and lineation. The authors study the influence of Sun angle, atmospheric conditions, and season on the images 


and infrared images, the author distinguishes between areas of sand deflation and accumulation.

Nossin, J. J., 1977, An integrated survey of the region Sousse, Tunisia: International Institute for Aerial Survey and Earth Sciences (ITC) Journal, v. 2, p. 336-357.

The paper outlines a multidisciplinary study of the Governorate Sousse, Tunisia, to identify development alternatives based on investigations of the land, water, and human resources. The author projects the benefits and consequences of each of these alternatives to 1986 . The availability of water is the chief constraint on industry, tourism, and agriculture. A linear programing model is used to outline the basic materials necessary for policy development.

Obuolowu, A., 1977, Qualititative interpretation of remotely sensed data as a key to mapping vegetative patterns in the western Sudan: Geographical Journal, v. 1.5, p. 13-20.

Monthly high resolution infrared radiometer (HRIR) data from Nimbus 3 are used to analyze changes in vegetation boundaries over the Sudan. The author suggests that the changes in vegetation are caused by changes in soil-moisture content which is controlled by the prevailing meteorological conditions. The author briefly reviews the capabilities of satellite remote sensing systems.

Otterman, Joseph, 1974, Baring high-albedo soils by overgrazing: a hypothesized desertification mechanism: Science, v. 186, p. 531-533.

The author compares the albedos of soils denuded by overgrazing with those of regions covered by vegetation and shows that denuded surfaces are cooler. The cooler surfaces may result in a decreased lifting of air necessary for cloud formation and precipitation, leading to regional desertification.

Otterman, Joseph, 1975, Reply to Jackson, R. D. and Idso, S. B.: Science, v. 189, p. 1013-1015. The author discusses the thermal characteristics of healthy leaves as a function of evapotranspiration and high albedo in the infrared portion of the electromagnetic spectrum. He discusses the contrast in Landsat band 7 reflectance between the Sinai and Negev Deserts and attributes the high albedo of the Sinai to the bare unstabilized soil.
Otterman, Joseph, 1977, Anthropogenic impact on the albedo of the Earth: Climatic Change, v. 1, p. 137-155.

The author analyzes the impact of people and animals on the surface albedo of the Earth. Low albedo is a result of dark plant debris accumulating on the crusted soil surface. The higher albedo is produced when overgrazing results in a trampled, crumbled soil. The author believes that overgrazing has a significant regional and global effect, and may have raised the surface albedo of the Earth by as much as 10 percent. He recommends seasonal mapping of surface albedo from satellite data.

Otterman, Joseph, 1978, Point sources and streaks of dust storms: a study of Landsat images and some inferences: Israel Meteorological Research Papers, v. 2, p. 233-243.

Analysis of Landsat images of intense dust storms indicates that the dust originates in point sources and flows in nearly horizontal streaks that maintain their shape in a horizontal flow for up to $100 \mathrm{~km}$. Particles are lifted by saltation which then increases friction at the surface. This increase explains the prevalence of point sources. The author suggests that prevention and countermeasures may be more effective in the case of a horizontal-flow regime than in the case of dust storms created by descending air masses.

Otterman, Joseph, and Fraser, R.S., 1976, Earthatmosphere system and surface reflectivities in arid regions from Landsat MSS data: Remote Sensing of Environment, v. 5, p. 247-266.

The authors compute ratios of the Earthatmosphere system (space) directional reflectivities in the nadir direction to the surface. Ratios are presented in graphs in which two water-vapor levels are plotted as a function of surface reflectivity at various Sun angles. The authors calculate reflectivities for a vertical direction in selected arid regions in Asia, Africa, and Central America from spectral-radiance levels of the MSS. They also compute surface reflectivities and estimate surface albedo for the entire solar spectrum.

Paylore, Patricia, ed., 1976a, Desertification: a world bibliography: Tucson, University of Arizona, Office of Arid Land Studies, $644 \mathrm{p}$.

This annotated bibliography of desertification is divided into the following sections: Worldwide, Saharan Region and Sahel, East Africa, Southern 
Africa, Middle East, U.S.S.R., Pakistan, India, Australia, South America, and North America. The sections are subdivided into individual countries. Each section contains a keyword and author index.

Paylore, Patricia, ed., 1976b, The Sonoran desert: a retrospective bibliography: Tucson, University of Arizona, Office of Arid Land Studies, $422 \mathrm{p}$.

The report contains a 777-entry annotated bibliography of papers on the Sonoran desert. Entries are listed by main subject and are cross-indexed. Seven entries are listed under remote sensing.

Pesce, Angelo, 1968, Gemini space photographs of Libya and Tibesti: Tripoli, Libya, Petroleum Exploration Society of Libya, $81 \mathrm{p}$.

The author uses Gemini photographs to trace a southward migration of sand and sand dunes and to recognize hydrographic systems.

Place, John, 1976, Monitoring change in land use over large regions, in U.S. Geological Survey Professional Paper 929, p. 230-233.

Landsat images of the Phoenix, Ariz., area are used to update maps and to identify the areas of greatest change in which more intensive survey techniques may then be applied.

Rapp, A., 1974, A review of desertification in Africa: water, vegetation, and man: Stockholm, Sweden, Secretariat for International Ecology, SIES Report no. 1, $77 \mathrm{p}$.

The author concludes that actual desertization, which term he prefers to desertification, is mainly induced as a result of overgrazing, overcultivation, wood cutting, and burning. The overexploitation by man destroys the plant cover beyond the required minimum coverage for protection of the soil against rapid soil erosion by water or wind. The author recommends surveying and monitoring of selected transects in Africa and elsewhere, as a basis for short-term and long-term actions. He also recommends using pilot trial plots of land to demonstrate ecologically sound methods of land use. He focuses particularly on analysis of quantity and type of soil particles in dust storms from drylands and desert areas by means of satellite images and ground checking (from Paylore, 1976a).
Rapp, A., 1976, Regional studies and proposals for development: in Rapp, A., Le Houerou, H. N., and Lundholm, B., eds., Can desert encroachment be stopped? A study with emphasis on Africa: Swedish Natural Science Research Council, Ecological Bulletin no. 24, p. 155-164.

Photographs from aerial reconnaissance surveys are used to map the desert boundaries and study vegetation in the Sudan.

Reining, Priscilla, ed., 1978a, Desertification papers: Washington, D.C., American Association for the Advancement of Science, $141 \mathrm{p}$.

The editor includes six background papers and four papers presented after the 1977 Nairobi Seminar on Desertification. The papers address the issues of measuring and monitoring desertification.

Reining, Priscilla, ed., 1978b, Handbook on desertification indicators: Washington, D.C., American Association for the Advancement of Science, $141 \mathrm{p}$.

At the 1977 United Nations Seminar on Desertification, a limited number of key signs or indicators of desertification were identified. The editor lists and discusses these indicators and suggests two principal ways in which remotely sensed data from aircraft and spacecraft may be used in conjunction with the indicators to study desertification. The images may be used to define an area for a stratified area frame sample, or they may be used in conjunction with other data to detect or assess specific features.

Robinove, C. J., 1979, Integrated terrain mapping with digital Landsat images in Queensland, Australia: U.S. Geological Survey Professional Paper 1102, $39 \mathrm{p}$.

The author uses Landsat images to produce integrated terrain maps of Queensland, Australia. The integrated terrain mapping combines several terrain features into each map unit. The units are more directly related to uses of the land and to methods of land management than are the single features alone. Terrain brightness, as measured by Landsat scanners, represents an integration of reflectance from the terrain features and is therefore more correlatable with integrated terrain units than with differentiated ones.

Robinove, C. J., Chavez, P. S., Jr. Gehring, D., and Holmgren, R., 1981, Arid land monitoring 


Theme extraction, or supervised classification, of data from Landsat computer-compatible tapes is valuable for arid land mapping. The authors establish suitable themes using an unsupervised parallelepiped technique, and find that the mapping can be accomplished at considerable savings over conventional mapping techniques.

Verstappen, H. T., 1979, Drought susceptibility survey and the concept of monitoring landscape ecology: Symposium on Drought in Botswana, Hanover, N.H., University Press, Proceedings, p. 75-83.

Desertification is believed to be caused by the cumulative effect of an anthropogenous and a climatic factor. The anthropogenous factor is the inappropriate use of land, particularly when population is increasing. The climatic factor is associated with secular and seasonal fluctuations. Both factors are interrelated and may reinforce each other. A decrease in vegetative cover and the resulting increase in albedo results in subsiding air currents in the margins of deserts. Rainfall then decreases, and vegetation further decreases. National Oceanic and Atmospheric Administration satellite data indicate that a reversal of the process may take place in areas where vegetation has reappeared because of a reduction in the number of livestock during drought. The reappearance of vegetation may help to introduce natural precipitation after a drought. Landsat images are used to reveal major patterns and to survey key areas, followed by stereoscopic observations of aerial photographs and associated fieldwork.

Vinogradov, B. V., 1976, Desertification forms as shown on aerial and space photos, in Glantz, M. H., ed., Desertification-Environmental degradation in and around arid lands: Colorado, Westview Press, p. 219.

Desertification can be identified on aerial and space photographs. Temporal data are considered to be the most reliable for monitoring desertification. The spectral reflectance coefficient is one of the major keys for monitoring desertification. The value of the coefficient is inversely proportional to the projected vegetation cover at decreased soil moisture and increased concentrations of dust.

White, L. P., 1975a, Monitoring desertification from space: Cambridge meeting on desertification, Cambridge, England, Proceedings, $p$. 28-31.
Photographs are useful for identifying smallscale individual changes in areas susceptible to desertification. However, such photographs are not useful for quantitative spectral measurements because the information they contain cannot be calibrated.

White, L. P., 1975b, Vegetation areas as indicators of changing environment: Cambridge meeting on desertification, Cambridge, England, Proceedings, p. 45-50.

Vegetation arcs, stripes, and ripples occur on flat to gently sloping surfaces where water moves as sheet wash in arid and semiarid environments. The author uses large-scale black-and-white and color aerial photographs to map the vegetation.

Williams, O. B., Svidendoup, H., and Wilcox, D. G., 1977, Australia: Gascoyne Basin-An associated case study: U.N. Conference on Desertification, Nairobi, 1977, Conference Document A/conf. 74/12, $177 \mathrm{p}$.

The Gascoyne Basin in western Australia, an area heavily grazed by sheep, has suffered severe rangeland degradation and erosion. Social, political, and economic aspects of the basin are described, and constraints to the control of desertification are noted with emphasis on practices to improve rangelands. Suggested programs include (1) reduction of sheep and removal of all livestock from seriously degraded areas, (2) renewal of certain perennial shrubs, (3) improved management and inspection of sheep and cattle stations, (4) monitoring of programs using large-scale aerial photographs and ground measurements, and (5) rangeland research and educational programs involving plant species identification and range assessment. Appendixes include information on pastoral leases, financial analysis for a typical station, general assessment of an individual station, and detailed description of rangeland types.

Worcester, B. K., and Dalsted, K. J., 1979, Application of remote sensing to detection of desertification processes, in Goodin, J. R., and Northington, D. K., eds., Arid land plant resources: Lubbock., Tex., International Center for Arid and Semi-Arid Land Studies, $p$. $622-628$.

Landsat data are excellent for monitoring desertification because they provide a broad synoptic view, repetitive coverage, nearly orthographic 
scenes, and multispectral capabilities. Digital data are available for computer analyses. The objectives of a desertification monitoring program are to assess existing conditions, to detect physical indicators of desertification, and to observe changes representative of improvements or deterioration of natural resources. Band 5 and false-color composite images show vegetation best, while bands 6 and 7 are better suited to hydrology. The authors believe that remote sensing methods are timely and cost-effective for monitoring desertification.

\$ U.S. GOVERNMENT PRINTING OFFICE: 1981 - 341-614/240 